\title{
Identification of interventions for better child road safety in Jordan
}

\author{
Khair Jadaan ${ }^{1, a}$, Chika Sakashita ${ }^{2}$, and Ruba Hikmat ${ }^{* 3}$ \\ ${ }^{1}$ Professor, Civil Engineering Department, University of Jordan, Amman, Jordan \\ 2 International Consultant, Global Road Safety Solutions Pty Ltd, Sydney, Australia. \\ ${ }^{3}$ Child Protection Specialist, UNICEF, Amman, Jordan
}

\begin{abstract}
Children of Jordan below 18 years are particularly at risk and their proportion of all casualties is rising reaching about $28 \%$ in 2016, yet limited research has been carried out to address this problem. This study investigates the magnitude and nature of the child road safety problem with the final aim of identifying the necessary interventions to improve child road safety in Jordan. Road crash death data were provided by the Jordan Traffic Institute. Additional data were sought through interviews with the Jordanian Government and other non-government stakeholders such as the UNICEF Makani Centres (community centres for children). A seat belt observational survey was also conducted. All the data were synthesised to provide a much better understanding of the magnitude and nature of the child road safety issue in Jordan. Potential interventions for Jordan to improve its child road safety situation are provided based on the present data analyse.
\end{abstract}

\section{Background}

In the most recent World Health Organization (WHO) Global Status Report on Road Safety [1] the rate of road deaths per 100,000 population in Jordan was estimated at 24.4, making it one of the worst road safety performing countries in the world. Pedestrians and passengers make up the majority (62.3\%) of the road deaths in Jordan with most of those pedestrian and passenger deaths suffered by children under the age 18 [1].

WHO reports traffic injuries are the leading cause of death for children between 5-14 years and young adults between 15-29 [1]. The problem is more acute in developing than developed countries. The results of a study in Bangladesh reported that one third of the pedestrians dying in road crashes were under the age of 16 years, leading to the development of a child road safety strategy to reduce child injuries and fatalities [2]. In India, research revealed that road crashes accounted for $55 \%$ of all child accidental death and in almost all of these, the unsafe behavior of child was considered to be at fault [3]. In Malaysia, road traffic injuries among children aged $0-19$ years account for about $35 \%$ of total admission to public hospitals [4].

Jordan is a lower middle-income country that has been experiencing persistent growth in population, economy, and motorization level. The annual population growth rate over the past few years is about $6 \%$ and children below 18 years of age constitute about $45 \%$ of the total population of about 9.9 million [5].

Along this growth, Jordan has also experienced a high level of traffic crashes. There were about 16,000 fatalities from all ages between the years 1989 and 2016, while children below the age of 18 years constitute about $26 \%$ of total casualties [6] with this proportion found to be increasing in recent years [7]. The lack of reliable data is a serious problem in most of developing countries, including Jordan. Therefore, it is quite reasonable to assume that the incidence of crashes is much larger than actually reported. Clearly, urgent actions are needed to improve the child road safety situation in Jordan.

A review of the literature identified many of the road safety studies in Jordan were general analyses of road

\footnotetext{
a Corresponding author: kjadaan@gmail.com
} 
crash data reported by the Jordan Traffic Institute (JTI). Past studies on pedestrian crashes have highlighted the overrepresentation of children in pedestrian casualties $[8,9]$. A hospital-based study on childhood injuries in Jordan suggested that school aged children suffered the greatest number of injuries and sustained the injuries most commonly at school followed by on roads and playgrounds [10]. Overall, research literature on road crash casualties specifically involving children in Jordan is limited.

This comprehensive study, the first of its type in Jordan, aims to determine the magnitude of and potential factors contributing to road related causalities among children and identify key opportunities to improve child road safety in Jordan.

\section{Methods}

This study was concerned with children under the age of 18. It was conducted in 2017. Road crash death data were obtained from the Jordan Traffic Institute. Data were also sought through interviews with the Jordanian Government and other non-government stakeholders such as parents and teachers at select public schools and UNICEF Makani Centres (community centres for children). Approval of interviews with parents and teachers at select public schools was granted from the Ministry of Education. All those interviewed provided consent to participate. The government stakeholders included the Jordan Traffic Institute, Central Traffic Directorate, Highway Patrol Directorate, Ministry of Public Works and Housing, Ministry of Municipalities, Ministry of Interior, Ministry of Education, Ministry of Transport and Greater Amman Municipality. A brief observational survey of seat belt wearing was also conducted. All the data were synthesised to provide a better understanding of the magnitude and possible risk factors of child road deaths and injuries in Jordan.

\section{Results}

\subsection{Magnitude of child road deaths in Jordan}

The crash data from the Jordan Traffic Institute provide a picture of magnitude of the child road safety problem in Jordan. In the 10 years between 2007 and 2016, Jordan lost 2,060

children under 18 . The 10-year data were analysed to provide annual average estimates of deaths by age group and Governate (Table 1) and by age group and road user group (Table 2).
The death data by age and Governate show that the three most populous Governate in Jordan - Amman, Irbid and Zarqa - have suffered the greatest number of child road deaths between 2007-2015 (Table 1). The data also show that all age groups under 18 are at risk of road deaths in Jordan, but younger children suffer a greater proportion of all deaths under 18 - in increasing order from ages 1217 (24\%), 6-11 (30\%) and 0-5 (46\%).

Table 1. Annual average (rounded to closest whole number) number of deaths by age group and Governate in Jordan

\begin{tabular}{|c|c|c|c|c|c|c|c|}
\hline $\begin{array}{l}\text { Age } \\
\text { Group }\end{array}$ & 0 to 2 & 3 to 5 & 6 to 8 & $\begin{array}{l}9 \text { to } \\
11\end{array}$ & $\begin{array}{l}12 \text { to } \\
14\end{array}$ & $\begin{array}{l}15 \text { to } \\
17\end{array}$ & $\begin{array}{l}\text { Total } \\
\text { under } \\
18\end{array}$ \\
\hline Amman & 18 & 22 & 13 & 13 & 10 & 11 & 87 \\
\hline Irbid & 8 & 10 & 6 & 6 & 4 & 5 & 39 \\
\hline Zarqa & 6 & 7 & 4 & 4 & 3 & 4 & 28 \\
\hline Balqa & 2 & 3 & 2 & 1 & 1 & 1 & 10 \\
\hline Karak & 1 & 2 & 1 & 1 & 1 & 1 & 7 \\
\hline Mafraq & 3 & 3 & 2 & 2 & 1 & 1 & 12 \\
\hline Ma'an & 0 & 1 & 0 & 0 & 0 & 0 & 1 \\
\hline Aqaba & 1 & 1 & 1 & 1 & 0 & 0 & 4 \\
\hline Madaba & 1 & 1 & 1 & 1 & 0 & 0 & 4 \\
\hline Tafilah & 0 & 1 & 0 & 0 & 0 & 0 & 1 \\
\hline Jerash & 1 & 1 & 1 & 1 & 0 & 1 & 5 \\
\hline Ajloun & 1 & 1 & 1 & 0 & 0 & 0 & 3 \\
\hline Total & 42 & 53 & 32 & 30 & 20 & 24 & 201 \\
\hline
\end{tabular}

The child death data by age and road users (pedestrians, drivers and passengers) show that children under 18 are at particularly significant risk as pedestrians $(55 \%$ of all crash deaths under 18$)$ and vehicle passengers ( $40 \%$ of all crash deaths under 18), making up $95 \%$ of the road crash deaths suffered by children under 18 in the last 10 years (Table 2). This is in stark contrast to pedestrians $(25 \%)$ and passengers (31\%) making up 56\% of deaths in adults 
aged 18 and over in Jordan and pedestrians (38\%) as well as passengers (36\%) making up $74 \%$ of child road deaths worldwide [11]. Again, younger children suffer a greater proportion of pedestrian and vehicle passenger deaths - in increasing order from ages 12-17 (21\%), 6-11 (30\%) and $0-5(48 \%)$.

Table 2. Annual average (rounded to closest whole number) number of deaths among children under 18 by age and road user group

\begin{tabular}{|l|l|l|l|l|}
\hline Age Group & Pedestrians & Drivers & Passengers & Total \\
\hline 0 to 2 & 19 & 2 & 25 & 46 \\
\hline 3 to 5 & 37 & 0 & 14 & 51 \\
\hline 6 to 8 & 21 & 0 & 10 & 31 \\
\hline 9 to 11 & 16 & 1 & 12 & 29 \\
\hline 12 to 14 & 11 & 2 & 11 & 24 \\
\hline 15 to 17 & 10 & 6 & 11 & 27 \\
\hline Total under 18 & 114 & 11 & 83 & 208 \\
\hline $\begin{array}{l}\text { Percentage by road } \\
\text { users }\end{array}$ & $55 \%$ & $5 \%$ & $40 \%$ & $100 \%$ \\
\hline
\end{tabular}

It is also notable that children aged $0-2$ and 9-17 were also killed as drivers in the past 10 years even though the legal licensing age is 18 . When consulted, the JTI explained that some children, especially between the ages 15 - 17 take the car without the knowledge of the parents and some children under the age 15 have been found in the driver seat at the time of the crash. The JTI suspect that the child moved a parked car. It is also not uncommon observation of children being nursed by an adult driver in Jordan, this may also have led to a child being killed in the driver's seat and being mis-recorded as the driver.

\subsection{Possible factors contributing to child road deaths and injuries}

The seat belt observational survey and the interviews with the Government stakeholders, parents and teachers of school children at select public schools and UNICEF Makani centres identified possible factors contributing to road crash deaths and injuries of children in Jordan.

The causes of casualty deaths identified by the Jordan Traffic Institute (JTI) were all related to human factors (e.g. Tail Gating, Not Taking the Necessary
Precautions While Driving, Using Incorrect Lane, Priorities false, Reversing Incorrect, Failing to Comply with Obligatory signs, Speed Limit Exceeding, Loss of Control While Driving, Incorrect Bending and Turning, Disregarding A Traffic Light Signal, Driving Opposite To Traffic Direction, Priority to Disallowing Pedestrian, Others). A few of these causes relate to excessive speed(e.g. Tailgating, Exceeding Speed Limit, Loss of Control). High travel speeds, speeding and noncompliance with traffic lights and other road rules were also commonly reported as a problem in Jordan in the interviews with Government and non-government stakeholders. However, non-use of seat belts was not included in the JTI data records. In addition, all the causes identified by the JTI were attributed to human factors and no causes were attributed to non-human factors such as infrastructure (e.g. Non-functional Street Lights; Hit Fixed Object on Roadside; Inappropriate Speed Limit) or vehicle (e.g. No Seat Belt Installed).

The seat belt observational survey revealed that seat belt wearing rates were very low in Jordan (Table 3). When compared with wearing rates in other countries, it is apparent that Jordan has the lowest wearing rate and especially lower wearing rates for children (Table 4). 
Table 3 . Seat belt wearing rates in Jordan

\begin{tabular}{|c|c|}
\hline \multicolumn{2}{|l|}{ Adults } \\
\hline Position & $\%$ Wearing a seat belt \\
\hline Driver & $23.5 \%$ \\
\hline Front seat passenger & $0 \%$ \\
\hline $\begin{array}{l}\text { Rear seat passenger (and } \\
\text { cargo area of trucks or vans) }\end{array}$ & $0 \%$ \\
\hline Weighted mean for sample & $15.8 \%$ \\
\hline \multicolumn{2}{|l|}{ Children aged $10-18$} \\
\hline Position & $\%$ Wearing a seat belt \\
\hline Driver & $\begin{array}{l}0 \% \text { (but children seen driving are quite rare with } \\
\text { only one child seen driving and so the sample is } \\
\text { too small to be reliable) }\end{array}$ \\
\hline Front seat passenger & $8.3 \%$ \\
\hline $\begin{array}{l}\text { Rear seat passenger (and } \\
\text { cargo area of trucks or vans) }\end{array}$ & $0 \%$ \\
\hline Weighted mean for sample & $2.7 \%$ \\
\hline \multicolumn{2}{|l|}{ Children under age 10} \\
\hline Position & $\%$ Wearing a seat belt \\
\hline Front seat passenger & $4.8 \%$ \\
\hline $\begin{array}{l}\text { Rear seat passenger (and } \\
\text { cargo area of trucks or vans) }\end{array}$ & $0 \%$ \\
\hline Weighted mean for sample & $1.2 \%$ \\
\hline
\end{tabular}

Table 4. Comparison of seat belt wearing rates in different countries

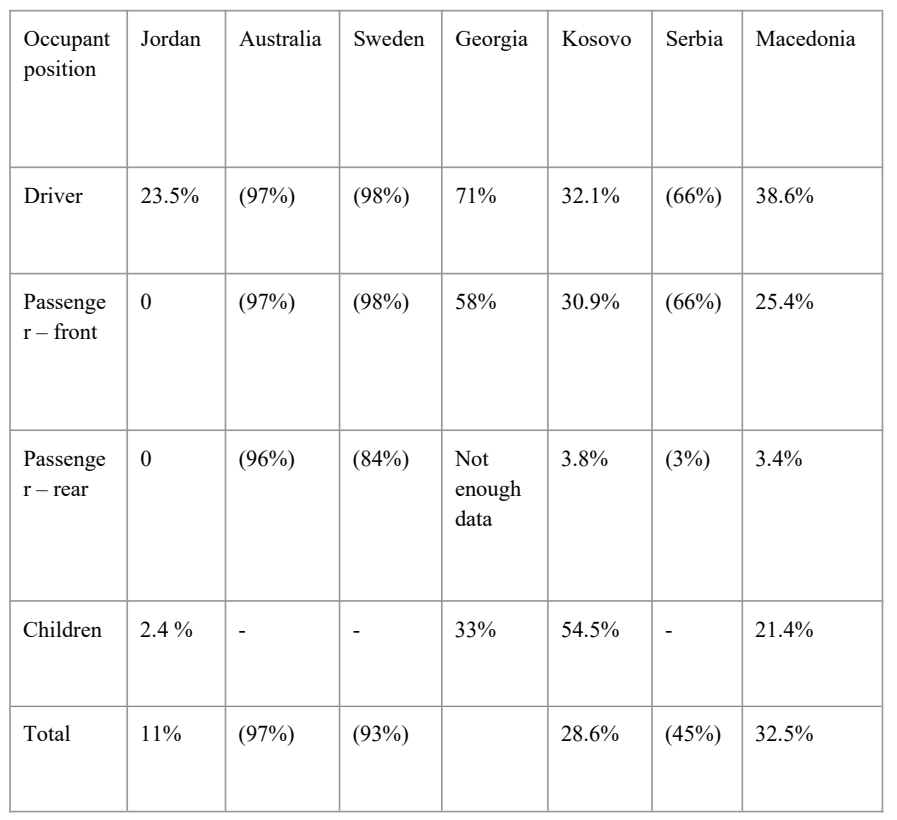

Source: Global Road Safety Solutions Pty Ltd. Figures in brackets are based on WHO [12]

While seat belt legislation exists, child restraint legislation does not exist in Jordan. However, children under 10 are required by law to sit in the back seats and yet the seat belt law only requires drivers and front seat passengers to wear seat belts. The usage of child restraints, whilst not nil, was extremely rare in Jordan.

It was also reported in the interviews that teenage boys even if unlicensed drive in Jordan and show speeding and stunt behaviours. High risks of young drivers especially males and unlicensed drivers are well established in the literature [13] and they are likely to in part account for the road deaths and injuries of children in Jordan. While data on the levels of enforcement could not be obtained, the abovementioned risk behaviours which are against existing laws in Jordan (e.g. seat belt laws, speed limits, licensing age of 18 and over) suggest the enforcement is generally weak.

Data on the total number of schools in Jordan and how many of those are placed on major roads could not be obtained. However, the present interviews revealed that schools along major roads with high traffic volume and schools with the main gate facing high volume traffic roads, at complex intersections or on curved roads are common. High risk locations of schools in Jordan are likely to contribute to a high risk of death and injury in children commuting to school. 
In addition, travel speeds do not appear to be well controlled around schools in Jordan. When teachers and parents were asked in the interviews about the speed limit around schools, they did not know. However, they reported to see cars pass the schools at speeds greater than $60 \mathrm{~km} / \mathrm{h}$. The interviews further revealed that clear and enforced school zones are not implemented in Jordan. All schools are advised to have a school sign and a $40 \mathrm{~km} / \mathrm{h}$ speed limit sign, but they are guidelines and not legal requirements.

The interview with government stakeholders also uncovered the lack of funding as a major barrier to improving road safety in Jordan, including child road safety. The interview also highlighted the lack of a national road safety management body and no particular agency was responsible for managing child road safety in Jordan.

\section{Discussion}

This study identified the magnitude of the child road safety problem and the possible factors contributing to the problem through a multi-method approach. The interviews identified some interventions are under development in Jordan. These included school zones, public transport, improving the walkability of Amman city and licence penalty point system. The present findings suggest certain other interventions have potential to improve the child road safety problem in Jordan. These are discussed in turn.

Jordan would benefit from making improvements to the current crash data collection and analysis mechanisms which will be able to produce more reliable fine-level crash data and allow in-depth analysis. For example, regular seat belt surveys can provide Jordan with data that can inform where and when enforcement is needed. Such data also provide Jordan with the capacity to monitor and evaluate the benefits of seat belt initiatives such as increased seat belt enforcement. Evaluation data not only have the benefit of improving practice but also sustaining political and public support for the initiatives.

A comprehensive seat belt law applying to all vehicle occupants anywhere and anytime is vital to improve seat belt wearing by children and therefore reduce the number of road deaths and injuries in children of Jordan. Mandating seat belts for all vehicle occupants including children in the back seats is critically needed in Jordan. Countries with seat belt laws that apply to all front and back seat occupants (e.g. Australia, Sweden) have high seat belt wearing rates for both front seat occupants (close to 100\%) and back seat occupants (well over 80\%).
Any exclusion clauses such as only for front seat occupants and only on highways can interfere with effective implementation of the law including enforcement. In addition, implementation of child restraint legislation mandating the use of child restraints based on age, height or weight will further help prevent deaths and injuries of children as vehicle passengers in Jordan.

The legal licensing age is 18 in Jordan yet younger drivers were reported in road crash death data. Interviews with parents and teachers confirmed that it is not uncommon to find underage drivers not only driving but also speeding and performing stunts in Jordan. A strict licensing scheme such as the Graduated Licensing Schemes (GLS) which require drivers to progress through incremental licensing stages with gradual lifting of restrictions is needed in Jordan. Under such schemes noncompliance with the restrictions result in heavy penalties. These schemes are shown to be effective in reducing risk taking and casualty crashes involving young drivers [14].

Jordan's plan to implement school zones should be fully supported. This study found high travel speed around schools is of particular concern. School zones must be clearly marked through highly visible speed limit signs of $30 \mathrm{~km} / \mathrm{h}$ or lower on every road the school property sits. Self-enforcing infrastructure measures to reduce travel speed such as speed humps at regular intervals throughout the school zones and marked and raised pedestrian crossing [15]

Leadership and political commitment backed with sustainable funding for road safety are clearly needed to urgently and effectively bring down the road crash deaths and injuries suffered by the children of Jordan. Jordan's child road safety problem can improve dramatically with the top decision-making positions of Jordan giving clear recognition of the road safety problem and embarking with appropriate policy, institutional and financial changes.

It is hopeful that a National Road Safety Strategy (NRSS) 2018 -2027 has been developed in Jordan.

The strategy is primarily based on two main safety approaches namely Safe System and Vision Zero [16]. Safe System thinking has been at the core of success for the best performing road safety countries and jurisdictions globally. Within a safe system the road transport system must be designed, built, maintained, operated and used to accommodate inevitable human errors and vulnerability of human bodies. That is, a safe system ensures that crash forces are not beyond the forces the human body can withstand, in the event of a crash. 
The Safe System thinking also drives a moral demand that people should not die or suffer debilitating injury on our roads. It accepts that human error is inevitable and thus that crashes are inevitable, but does not accept that death and serious injury are inevitable consequences of these crashes.

Vision Zero policy requires that fatalities and serious injuries are reduced to zero by a specific target year. The national road safety work in Jordan should be based on a refusal to accept human deaths or lifelong suffering as a result of road crashes. A successful implementation of the National Road Safety Strategy 2018 -2027 in Jordan may bring reductions in child road deaths and injuries in Jordan.

\section{Acknowledgements}

This study was funded and supported by UNICEF Jordan. The authors also acknowledged the cooperation and collaboration of the government stakeholders, nongovernment stakeholders, and UNICEF Makani Centres in Jordan.

\section{References}

1.WHO, Global status report on road safety. World Health Organisation: Geneva (2018).

2.M. Hoque, H. Mahmud, A. Azad, S. Sohel, S. Sarkar. The Risk of Children in Road Traffic Accidents in Bangladesh. WEB international conference, $20^{\text {th }} \mathrm{Jan}$. (2009)

3.H. Singh, A. Aggarwal D. Fatal Road Traffic Accidents among Young Children. J Indian Acad Forensic Med, 32(4). (2010).

4.N. Mohamed N., W. Voon. An Overview of Road Traffic Injuries Among Children in Malaysia and Its Implication on Road Traffic Injury Prevention Strategy, Research Report, Malaysian Institute of Road Safety Research(MIROS). (2011).

5.Department of Statistics, Jordan Statistical Yearbook, Amman Jordan. (2018)

6.k. Jadaan, M.Al-Fayyad, and H. Gammoh, Prediction of Road Traffic Accidents in Jordan using Artificial
Neural Network. Journal of Traffic and Logistics Engineering, 2: 92-94. (2014)

7.K. Jadaan, H. Gammoh, S. Alrafayah, E. Braizat. Road Traffic Injuries and Fatalities Among Children in Jordan. The International Conference on Advances in Software, Control and Mechanical Engineering (ICSCME'2015). Antalya, Turkey. Sept. 7-8. (2015)

8.G. Al-Khateeb. Analysis of Accident Data and Evaluation of Leading Causes for Traffic Accidents in Jordan. Jordan Journal of Civil Engineering, 4(2):76-94. (2010)

9.H. Al Masaeid. Traffic Accidents in Jordan. Jordan Journal of Civil Engineering, 4(2):331-343. (2009)

10.M. Fa'ouri and F. Najdawi. Patterns of childhood injuries. Journal of the Royal Medical Services. 9(2):35-39. (2002)

11.WHO, Ten strategies for keeping children safe on the road. World Health Organization: Geneva (2015) http://apps.who.int/iris/bitstream/10665/162176/1/W HO_NMH_NVI_15.3_eng.pdf

12.WHO, Global status report on road safety. World Health Organisation: Geneva. (2015)

13.C. Sakashita, A. Graham, M. de Roos, S. Croft and M. Elliot. "Comparing provisional and unrestricted licence holders on speeding offences and crash rates." Paper in Proceedings of the Australasian Road Safety Research Policing and Education Conference, Melbourne, Australia, 17-19 October 2007. (2007)

14.L. Hartling, N. Wiebe, K. Russell, J. Petruk, C. Spinola, \& T. Klassen. Graduated driver licensing for reducing motor vehicle crashes among young drivers. Cochrane Database Syst Rev, 2(2). (2004)

15.M. de Roos. and F. Marsh, Speed limits: Getting the limit right - the first step in effective Speed Management. Journal of the Australasian College of Road Safety, 28(2), 55-59. (2017)

16.K. Jadaan, National Road safety strategy 2018 - 2027, a report submitted to the Minister of Transport, Jordan. (2018) 